\title{
PENANGANAN KEBUTUHAN AIR DAN KERACUNAN PIRIT DI DAERAH IRIGASI RAWA KECAMATAN JEJANGKIT KABUPATEN BARITO KUALA DENGAN MEMPERGUNAKAN MODEL DUFLOW
}

\author{
Engelbertus Fajar Yudianto ${ }^{1}$, Ussy Andawayanti ${ }^{2}$, Tri Budi Prayogo ${ }^{2}$ \\ ${ }^{1}$ Mahasiswa Magister Sumber Daya Air, Fakultas Teknik, Universitas Brawijaya \\ ${ }^{2}$ Dosen Magister Sumber Daya Air, Fakultas Teknik, Universitas Brawijaya ${ }^{2}$
}

\begin{abstract}
ABSTRAK : Rekomendasi dalam upaya peningkatan produksi pangan khususnya padi sangat di butuhkan saat ini, hal ini di akibatkan peningkatan kebutuhan akan pangan yang semakin tinggi. Salah satunya dengan melakukan perluasan areal pertanian ke lahan sub optimal khususnya lahan pertanian pasang surut. Penelitian ini yang bertujuan untuk dapat memberikan rekomendasi untuk mengatasi permasalahan yang terjadi pada lahan rawa pasang surut Kecamatan Jejangkit dengan menggunakan program Duflow. Dari hasil simulasi program menunjukkan tata air yang ada tidak mampu mensuplai air pada lahan Hal ini terlihat dari hasil model yang menunjukkan tinggi muka air berada di 1,293 meter sedangkan elevasi dasar lahan berada di 1,31 meter. Untuk mengatasi permasalahan tersebut maka pompa menjadi rekomendasi solusi dalam mengatasi permasalahan kebutuhan air dan juga mencegah pirit untuk dapat teroksidasi. Simulasi Duflow menunjukkan bahwa pompa mampu menaikan tinggi muka air dari 1,293 meter menjadi 1,51 meter hal ini tentu saja mampu mengatasi kebutuhan air dan mencegah resiko terjadinya oksidasi pirit karena adanya genangan pada lahan.
\end{abstract}

Kata kunci : lahan, pasang surut, pompa, genangan, pirit

\begin{abstract}
Recomendation to effort the enhencement of food production its realy needs now, because the elevation of pupulation growth every year more increasing. One of the recomendation is by doing an expansion to the sub optimal farm lands, especialy tidal land farming. This study aims to provide the recommendations to resolve the problems that occurred in the District of jejangkit tidal land using Duflow program. Simulation results show that the water management its not capable to supplying water to the farm land. Apparent from the results of the model indicate that water levels are at 1,293 meters while the bottom elevation of the land located at 1.31 meters. To solve the problem the pump its recomended to used so its can fulfilled the water requirements and can prevent the risk of pyrite to oxidate. Simulation of Duflow indicates that the pump is able to raise the height of the face of the waters of 1.293 meters become 1.51 metres of course it is capable to fulfilled the needs of water and prevent the risk of of pyrite to oxidate due the inundation on the land.
\end{abstract}

Keywords: land, tidal, pumps, puddle, pyrite

Pertambahan jumlah penduduk Indonesia yang di prediksi akan semakin meningkat dalam kurun waktu empat puluh tahun kedepan hal ini di akibatkan besarnya laju pertumbuhan penduduk di Indonesia 1,5\% dari total jumlah penduduk Indonesia per tahun (Khairul,2015). Pertambahan jumlah penduduk yang semakin pesat tentu akan membuat kebutuhan akan pangan juga meningkat. Keadaan ini dapat menjadi motivator untuk mencari pemecahan 
masalah dalam menangani produksi padi. Salah satunya dengan melakukan perluasan areal pertanian ke lahan sub optimal (lahan rawa pasang surut).

Kalimantan Selatan yang merupakan 10 besar kontributor padi di Indonesia dengan produksi pada tahun 2010 sebesar \pm 1 ,9 juta ton atau 2,8\%. Sementara itu, Kabupaten Barito Kuala merupakan kontributor terbesar di Provinsi Kalimantan Selatan dari 12 Kabupaten/Kota dengan produksi \pm 330 ribu ton atau 16,6 \% (BPS, 2015). Dengan luas wilayah \pm 300 ribu ha Kabupaten Barito Kuala didominasi lahan pasang surut seluas \pm 300 ribu ha $(96,1 \%)$ dan sisanya \pm 11 ribu ha $(3,9 \%)$ lahan lebak. Lahan pasang surut potensial Kabupaten Barito Kuala seluas \pm 120 ribu ha yang terdiri dari luapan tipe A $(49,7 \%)$, tipe luapan B $(31,9 \%)$ dan tipe luapan C $(18,4 \%)$. Sementara luas persawahan fungsional seluas \pm 100 ribu ha, sehingga potensi pengembangan lahan masih cukup memungkinkan. Kecamatan Jejangkit merupakan salah satu sentra tanaman pangan di Kabupaten Barito Kuala Provinsi Kalimantan Selatan dengan luas lahan sebesar \pm 3 ribu ha (BPS, 2015).

Kecamatan Jejangkit memiliki luasan daerah pasang surut $\pm 3000 \mathrm{Ha}$ dan rata-rata hasil produksi padi sawah mencapai 3,3 Ton/Ha (BPS, 2015). Rendahnya produktifitas pada persawahan pasang surut di Kecamatan ini antara lain dikarenakan oleh sifat dan ciri lahan dengan tingkat kesuburan tanah yang rendah dan lahan dalam keadaan ekstrim,, dimana pada saat musim hujan lahan tergenang, sebaliknya saat musim kemarau lahan kekeringan (Balai Rawa, 2014). Kondisi infrastruktur jaringan tata air pada lahan rawa persawahan pasang surut yang tidak optimal juga menyebabkan petani hanya dapat bercocok tanam satu kali setahun.

Berdasarkan permasalahan tata air di tanah pertanian rawa Kecamatan Jejangkit Kabupaten Barito Kuala, maka penelitian dalam kajian ini memiliki tujuan untuk mengetahui bagaimana kondisi eksisting tata air pada daerah rawa Kecamatan Jejangkit, serta rekomendasi apa yang dapat diterapkan pada lahan persawahan untuk mengatasi permasalahan kebutuhan air pada daerah rawa Kecamatan Jejangkit. Sehingga dapat diketahui bagaimana kondisi lahan setelah adanya penerapan rekomendasi tersebut untuk mengatasi permasalahan kebutuhan air pada daerah rawa Kecamatan Jejangkit

\section{BAHAN DAN METODE Rawa}

Rawa sebagai jaringan sumber daya air adalah genangan air terus menerus atau musiman yang terbentuk secara alamiah merupakan satu kesatuan jaringan sumber daya air dan mempunyai ciri-ciri khusus secara phisik, kimiawi dan biologis (Suhardjono,2010). Ciri fisik rawa pada umumnya kondisi tanahnya cekung dengan topografi relatif datar. Ciri kimiawi pada umumnya derajat keasaman airnya rendah dan/atau tanahnya bersifat anorganik atau mengandung pirit dan ciri biologis rawa pada umumnya terdapat flora dan fauna yang spesifik.

Daerah rawa dapat dibedakan dalam dua sub kelompok, yaitu rawa pantai dan rawa pedalaman. Karakteristik rawa pantai dipengaruhi fluktuasi pasang surut sedangkan rawa pedalaman dipengaruhi adanya pengaruh banjir sungai pada bantarannya.

Menurut morfologinya rawa dapat dibagi menjadi :

a. Tanggul alam yang pada umumnya diisi oleh bahan sedimen mineral dengan susunan fraksi lebih kasar.

b. Rawa belakang yang terletak di bagian tengahan antara dua sungai yang bila terisi gambut akan membentuk kubah gambut.

Hidro topografi dapat dibedakan menjadi empat klasifikasi sebagai berikut :

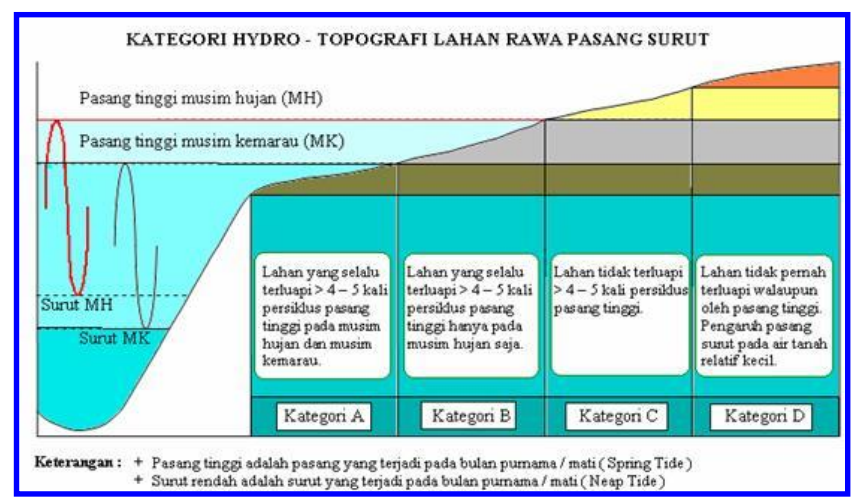

Gambar 1 Klasifikasi Hidrotopografi Sumber : Balai Rawa,2014

\section{Klasifikasi A}

Merupakan areal lahan rawa yang terdapat terluapi air pasang, baik di musim hujan maupun di musim kemarau. Permukaan lahan pada umumnya masih lebih rendah jika di bandingkan dengan elevasi air pasang rata-rata.

2. Klasifikasi B 
Merupakan areal lahan rawa yang hanya dapat terluapi air pasang di musim hujan. Permukaan lahan uumnya masih lebih tinggi dari elevasi air pasang tinggi ratarata di musim kemarau, namun masih rendah jika dibandingkan elevasi air pasang tinggi rata-rata di musim hujan.

3. Klasifikasi C

Merupakan lahan rawa yang tidak dapat terluapi oleh air pasang sepanjang waktu atau hanya kadang-kadang saja. Permukaan lahan umumnya relatif lebih tinggi jika dibandingkan klasifikasi A dan $\mathrm{B}$, sehingga air pasang hanya berpengaruh pada muka airtanah dengan kedalaman kurang dari $50 \mathrm{~cm}$ dari permukaan lahan

4. Klasifikasi D

Merupakan lahan rawa yang cukup tinggi sehingga sama sekali tidak dapat terjangkau oleh luapan air pasang ( lebih menyerupai lahan kering). Permukaan air tanah umumnya lebih dalam dari $50 \mathrm{~cm}$ dari permukaan lahan.

Sedangkan hidrotopografi lahan rawa lebak akibat pasang surutnya air di sungai sebagai dampak pasang surut di laut dan suplai air dari bagian sungai yang ada di hulu yaitu :

1. Lebak pematang, daerah ini memiliki genangan relatif dangkal dengan lahan yang berelevasi pada kedalaman lebih kecil dari 0,5 - 0,6 $\mathrm{m}$ di bawah muka air tinggi dengan periode waktu tergenang relatif pendek .

2. Lebak Tengahan, daerah ini memiliki genangan relatif agak dalam dengan lahan yang berelevasi pada kedalaman mencapai 0,6-1 $\mathrm{m}$ di bawah muka air tinggi, dengan periode tergenangnya relatif agak lama.

3. Lebak Dalam, daerah ini memiliki genangan relatif agak dalam dengan lahan yang berelevasi pada kedalaman mencapai 1-2 m dibawah permukaan air tinggi serta memiliki periode tergenang relatif sangat lama ( tergenang terus meneurus) dan tidak mempunyai kemampuan drainase lahan.

Pengelolaan air di lahan rawa dapat diartikan sebagai pemanfaatan secara tepat untuk keperluan domestik, meningkatkan produksi tanaman. Diantaranya untuk kebutuhan evapotranspirasi, pembuangan kelebihan air, mencegah terbentuknya bahan toksik dan melindi bahan toksik yang terjadi, serta mencegah penurunan muka tanah (sarwani.2012). Berdasarkan Peraturan Pemerintah Nomor 73 tahun 2013 irigasi rawa dapat diartikan sebagai usaha penyediaan, pengaturan dan pembuangan melalui jaringan irigasi rawa pada kawasan budi daya pertanian.

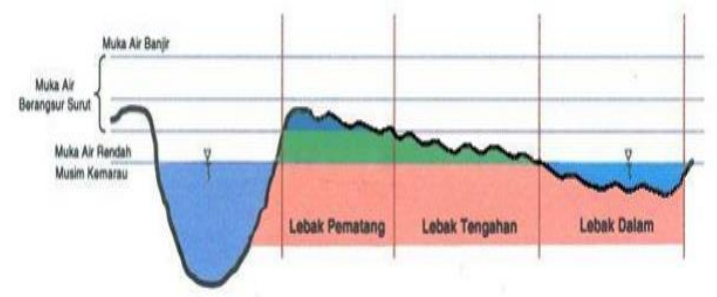

Gambar 2 Hidrotofografi Rawa Lebak
Sumber: Balai Rawa,2014

\section{Kebutuhan Air Irigasi}

Kebutuhan air irigasi yang perlu disediakan pada pintu pengambilan (intake) dapat dihitung dengan persamaan sebagai berikut :

$$
\mathrm{IR}=\frac{N F R x A}{\eta}
$$

dengan :

IR = Debit kebutuhan air irigasi pada pintu pengambilan $\left(\mathrm{m}^{3} / \mathrm{dt}\right)$

NFR = Kebutuhan air di sawah (lt/dt/ha)

$\mathrm{A} \quad=$ Luas lahan yang diairi (ha)

$\eta \quad=$ Efisiensi Irigasi

Kebutuhan air tanaman adalah sejumlah air yang dibutuhkan untuk mengganti air yang hilang akibat penguapan. Kebutuhan air tanaman (ET) tergantung dari besarnya evapotranspirasi potensial dikalikan dengan faktor koefisien tanaman. (Suhardjono, 1994:12) :

$$
\mathrm{ET}=\mathrm{k} . \mathrm{ETo}
$$

dengan :

ET = Kebutuhan air tanaman $(\mathrm{mm} / \mathrm{hari})$

$\mathrm{K}=$ Koefisien tanaman

ETo $=$ Evapotranspirasi potensial $(\mathrm{mm} / \mathrm{hari})$

Evapotranspirasi merupakan gabungan dari proses penguapan air bebas (evaporasi) dan penguapan melalui tanaman (transpirasi) (Hadisusanto,2010).Dalam studi ini digunakan rumus pendekatan Penman, Penman sangat sesuai dengan kondisi daerah di Indonesia yang beriklim tropis. Besarnya evapotranspirasi potensial dapat dibilang dengan menggunakan Penman (Hadisusanto,2010).

$$
\text { Eto }=\mathrm{c} \text {. Et* }
$$

Eto* $=$ W. $(0.7 \cdot R s-R n 1)+(1-W) \cdot f(u) \cdot($ ea-ed) $(4)$

Dengan :

Eto* $^{*}$ Evaporasi potensial sebelum dikoreksi/ evaporasi mula air bebas (mm/hari)

$\mathrm{W}=$ Faktor yang berhubungan dengan suhu (t) dan elevasi daerah. 
Rs = Radiasi gelombang pendek, dalam setahun evaporasi ekivalen ( $\mathrm{mm} / \mathrm{hari}$ )

$=(0,25+0.54 \mathrm{n} / \mathrm{N}) \cdot \mathrm{Ra}$

$\mathrm{Ra}=$ Radiasi gelombang pendek yang memenuhi batas luar atmosfer atau Angka angot (mm/hari)

Rn1 = Radiasi bersih gelombang panjang (mm/hari).

$=\mathrm{f}(\mathrm{t}) \cdot \mathrm{f}(\mathrm{ed}) \cdot \mathrm{F}(\mathrm{n} / \mathrm{N})$

$\mathrm{f}(\mathrm{t})=$ Fungsi suhu

$=\sigma \cdot \mathrm{Ta}^{4}$

$\mathrm{f}(\mathrm{ad})=$ Fungsi tekanan uap

$$
=0,344-0,44 \mathrm{ed}^{0.5}
$$

$\mathrm{f}(\mathrm{n} / \mathrm{N})=0,1+(1+\mathrm{u} / 100)$

$\mathrm{f}(\mathrm{u})=$ fungsi kecepatan angin pada ketinggian $2,00 \mathrm{~m}(\mathrm{~m} / \mathrm{detik})$

$=0,27(1+\mathrm{u} / 100)$

ea $=$ Perbedaan tekanan uap jenuh dengan tekanan uap sebenarnya

ed $=$ ea. $\mathrm{Rh}$

$\mathrm{Rh}=$ Kelembapan relatif $(\%)$

Perhitungan kebutuhan bersih air irigasi di sawah untuk tanaman padi pada daerah persawahan diperoleh dengan persamaan sebagai berikut:

$\mathrm{NFR}=\mathrm{ET}+\mathrm{P}-\mathrm{R}_{\mathrm{eff}}+\mathrm{WLR}$

Kebutuhan air irigasi untuk tanaman padi

$$
\mathrm{IR} \quad=\mathrm{NFR} / \eta
$$

Kebutuhan air irigasi untuk tanaman palawija

$$
\mathrm{IR}=\left(\text { Etc }-\mathrm{R}_{\mathrm{eff}}\right) / \eta
$$

dengan :

NFR = Kebutuhan air di sawah (mm/hari)

ET = Kebutuhan air tanaman ( $\mathrm{mm} / \mathrm{hari})$

$\mathrm{P} \quad=$ Perkolasi $(\mathrm{mm} / \mathrm{hari})$

$\mathrm{R}_{\mathrm{eff}} \quad=$ Curah hujan efektif (mm/hari)

$$
\begin{array}{ll}
\text { WLR } & =\text { Pergantian lapisan air }(\mathrm{mm} / \text { hari }) \\
\eta & =\text { Efisiensi irigasi }
\end{array}
$$

\section{Duflow}

program DuFlow adalah suatu model numerik yang memecahkan persamaan kontinuitas dan momentum dengan menggunakan cara selisih hingga menurut pembaganan Preissman. Perhitungan dengan model DuFlow ini dilakukan dengan membagi panjang saluran $\mathrm{L}$ kedalam beberapa ruas (section) dengan panjang ruas $\Delta \mathrm{x}$ (panjang ruas bisa tidak sama) dan ruas-ruas ini dibatasi oleh titik simpul (node), seperti dapat dilihat pada gambar dibawah ini. Selanjutnya harga parameter muka air, $\eta$ dan debit $Q$, dihitung pada tiap titik node. Namun, dalam program DuFlow, hasil perhitungan muka air diberikan pada titik simpul, sedang perhitungan debit diberikan di tengah ruas.

Pada DUFLOW, skema jaringan saluran (network) berikut komponennya ditunjukkan dalam skema yang terdiri dari titik nodal (node), ruas (section), dan bangunan (structure). Di tempat yang telah disediakan dimasukkan data ruas yang menghubungkan dua titik.

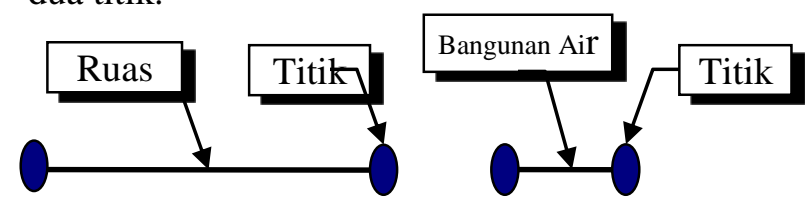

Gambar 3 Komponen skema tata letak jaringan irigasi Sumber : Balai Rawa, 2014

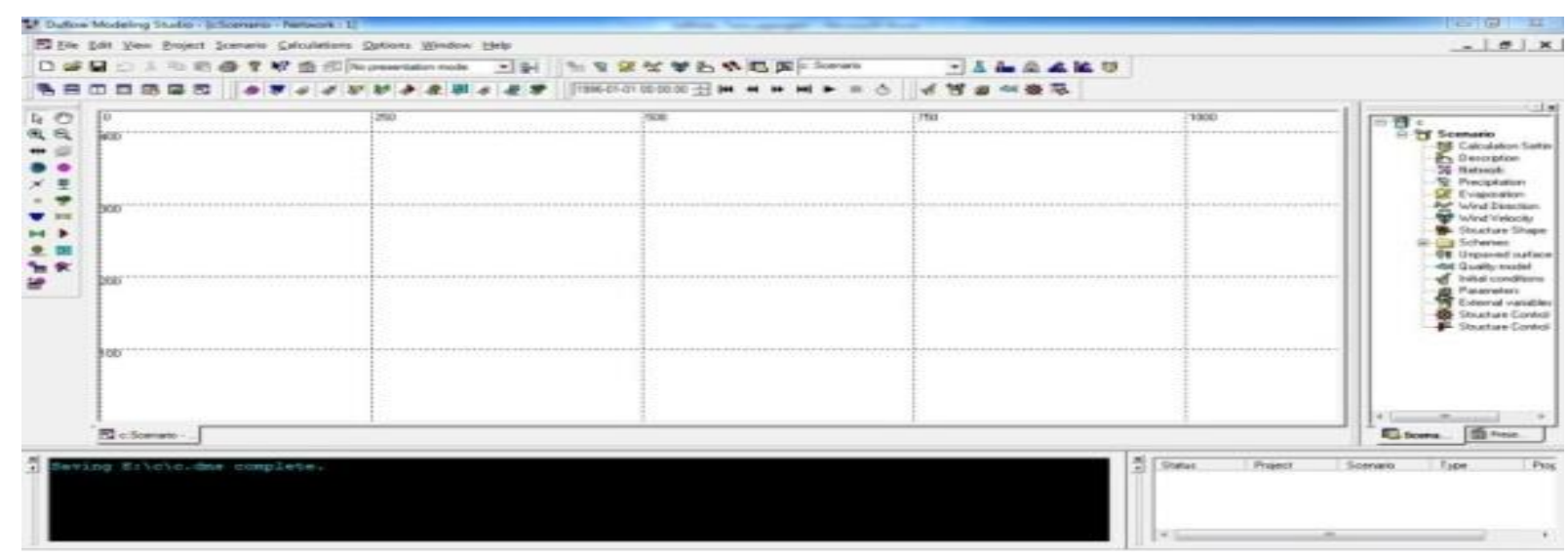

Gambar 4 Tampilan Duflow

Sumber : Hasil Analisa

\section{Lokasi Studi}

Lokasi yang akan dijadikan tempat untuk kajian studi adalah Irigasi Rawa Pasang Surut
Kecamatan Jejangkit Jejangkit Kabupaten Barito Kuala Provinsi Kalimantan Selatan. Kecamatan Jejangkit Memiliki Luas 203 km$^{2}$ 
dengan luas daerah pasang surut $\pm 3000 \mathrm{Ha}$ denga rata-rata hasil produksi padi mencapai 3,3 ton/Ha (BPS,2015).

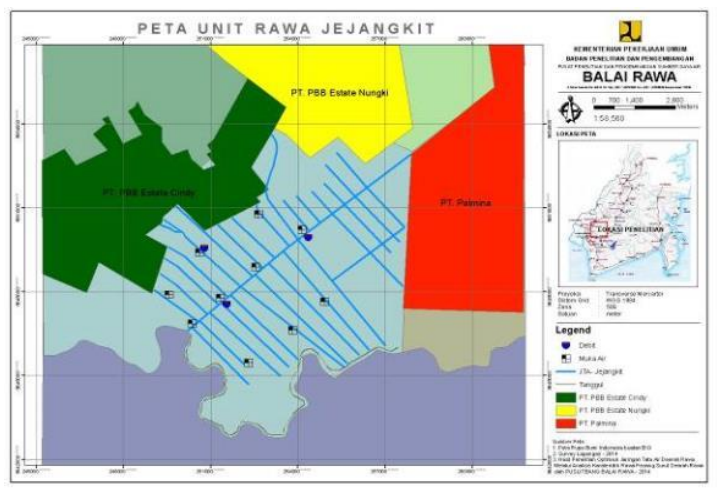

Gambar 5 Peta Unit Rawa Jejangkit Sumber : Balai Rawa, 2014

\section{Pengumpulan Data}

Data-data yang digunakan dalam penelitian ini berupa data sekunder, data yang di maksud adalah sebagai berikut:
1. Data Curah Hujan
2. Data Klimatologi
3. Data Topografi
4. Data profil saluran
5. Data pasang surut
6. Data pirit

\section{Pengolahan Data}

Tahapan analisis pada penelitian ini adalah sebagai berikut:

1. Menggunakan metode polygon thiessen untuk mengetahui hujan rata-rata pada daerah Kecamatan Jejangkit serta stasiun mana yang memiliki pengaruh pada daerah tersebut.

2. Menghitung evapotranspirasi dengan menggunakan metode penman modifikasi.

3. Menghitung curah hujan efektif dengan menggunakan metode basic year

4. Menghitung kebutuhan air pada saat penyiapan lahan

5. Menghitung kebutuhan air bersih pada lahan pada saat tanam

6. Membuat pembaganan model dengan menggunakan software Duflow 3.6, dengan tahapannya :

a. Memasukkan peta unit rawa Jejangkit kedalam model sebagai latar belakang (layer background)

b. Memasukkan node, section, cross section kedalam latar belakang. c. Memasukkan informasi kedalam cross section yang berisi data profil melintang saluran.

d. Memasukkan data pasang surut pada model sebagai boundary condition.

7. Running test model

8. Kalibrasi model dengan menggunakan metode regresi sederhana dan RMSE

9. Menganalisa kondisi eksisting lahan berdasarkan hasil model

10. Melakukan pengembangan model berdasarkan permasalahan yang terjadi berdasarkan dari hasil analisa kondisi lahan eksisting pada model.

11. Menganalisa hasil pengaruh pengembangan model terhadap lahan sawah pada lokasi studi.

\section{HASIL DAN PEMBAHASAN Analis Hidrologi}

Di karenakan penyebaran stasiun hujan yang tidak merata pada lokasi study maka di gunakan Metode Polygon Thiessen untuk mengetahui hujan rata-rata pada kecamatan Jejangkit dan mengetahui stasiun mana yang sangat berpengaruh pada Daerah Pertanian Irigasi Rawa Kecamatan Jejangkit

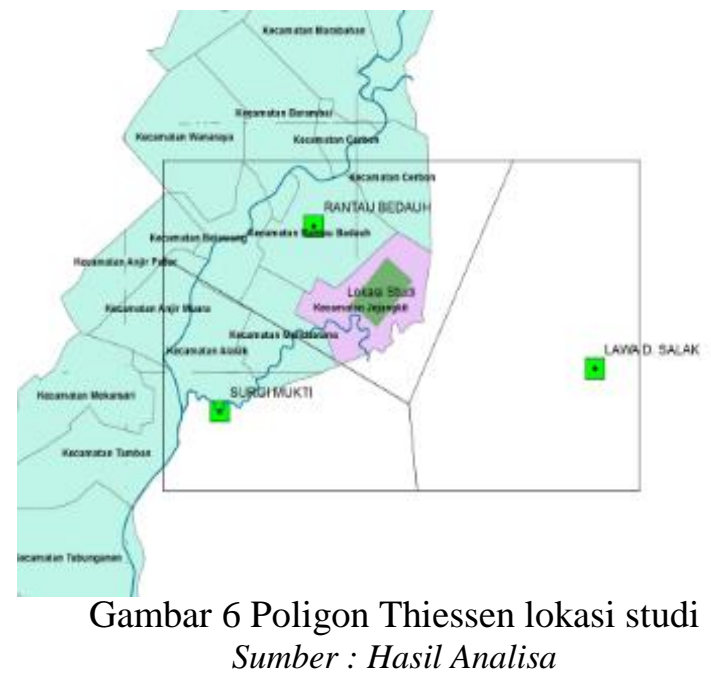

Tabel 1 Luas daerah hasil Poligon Thissen

\begin{tabular}{||c|r|r||}
\hline \hline Stasiun Hujan & Luas $\left(\mathbf{k m}^{2}\right)$ & \multicolumn{1}{|c|}{ Kr } \\
\hline \hline Rantau Bedauh & 130.6 & 1.00 \\
\hline Surgi Mufti & 0.217688 & 0.00 \\
\hline Lawa D Salak & 0.000 & 0.00 \\
\hline & & \\
\hline \hline Jumlah: & 130.817688 & 1.00 \\
\hline
\end{tabular}

Sumber : Hasil Analisa 
Dari Tabel 1 dapat dilihat bahwa Stasiun Hujan Rantau Bedauh mewakili 130,6 Km² dengan koefisien thissen 1.00 sehingga stasiun Rantau Bedauh yang memiliki pengaruh terbesar pada lokasi studi.

Besarnya evapotranspirasi potensial pada penelitian ini dihitung menggunakan metode Penman modifikasi. Dari hasil perhitungan besarnya evapotranspirasi potensial yang terjadi adalah :

$$
\begin{aligned}
\mathrm{ET}^{*}= & \mathrm{w}(0.75 \mathrm{Rs}-\mathrm{Rn} 1)+(1-\mathrm{w}) \mathrm{f}(\mathrm{u})(\mathrm{ea}- \\
& \mathrm{ed}) \\
= & 0.775(0.75 \times 6,6220-0.6292)+0.22 \\
& \mathrm{x} 0.7365 \times 7.184 \\
= & 4.2841 \mathrm{~mm} / \mathrm{hari} \\
\text { ETo }= & \mathrm{ET}^{*} \times \mathrm{c} \\
= & 4.2841 \times 1.1 \\
= & 4.7125 \mathrm{~mm} / \mathrm{hari}
\end{aligned}
$$

Curah hujan efektif pada lahan studi dari hasil perhitungang dengan menggunakan metode basic year adalah:

$$
\begin{aligned}
\text { Curah Hujan Effektif } & =0.7 \times \mathrm{R}_{80} / \mathrm{n} \\
& =0.7 \times 40 / 10 \\
& =2.80 \mathrm{~mm} / \mathrm{hari}
\end{aligned}
$$

Waktu yang dibutuhkan untuk penyiapan lahan biasanya dilakukan antara 20 - 30 hari. Pada studi ini pengolahan lahan dilakukan selama 30 hari, sehingga

Kebutuhan air penyiapan lahan (PL)

Adalah :

$$
\begin{aligned}
& =\left(\mathrm{Mx} \mathrm{e}^{\mathrm{k}}\right) /\left(\mathrm{e}^{\mathrm{k}}-1\right) \\
& =\left(7.43 \times 2.72^{1.02}\right) /\left(2.72^{1.02}-1\right) \\
& =12.59 \mathrm{~mm} / \text { hari }
\end{aligned}
$$

Sedangkan untuk kebutuhan air bersih pada saat tanam adalah :

Kebutuhan Air Bersih

$$
\begin{aligned}
(\mathrm{NFR})= & \left(\text { Kebutuhan Air Kotor }-\left(\mathrm{CH}_{\mathrm{ef}} \times\right. \text { Rasio }\right. \\
& \quad \text { luas total })) \times 10000 /(24 \times 60 \times 60) \\
= & (3.35-(2.80 \times 0.34)) \times 10000 / 86400 \\
= & 0.28 \mathrm{lt} / \mathrm{dt} / \mathrm{ha}
\end{aligned}
$$

\section{Analis Model Eksisting}

Dari hasil pembaganan model dengan menggunakan software Duflow 3.6 dapat di lihat pada gambar 7 dibawah ini

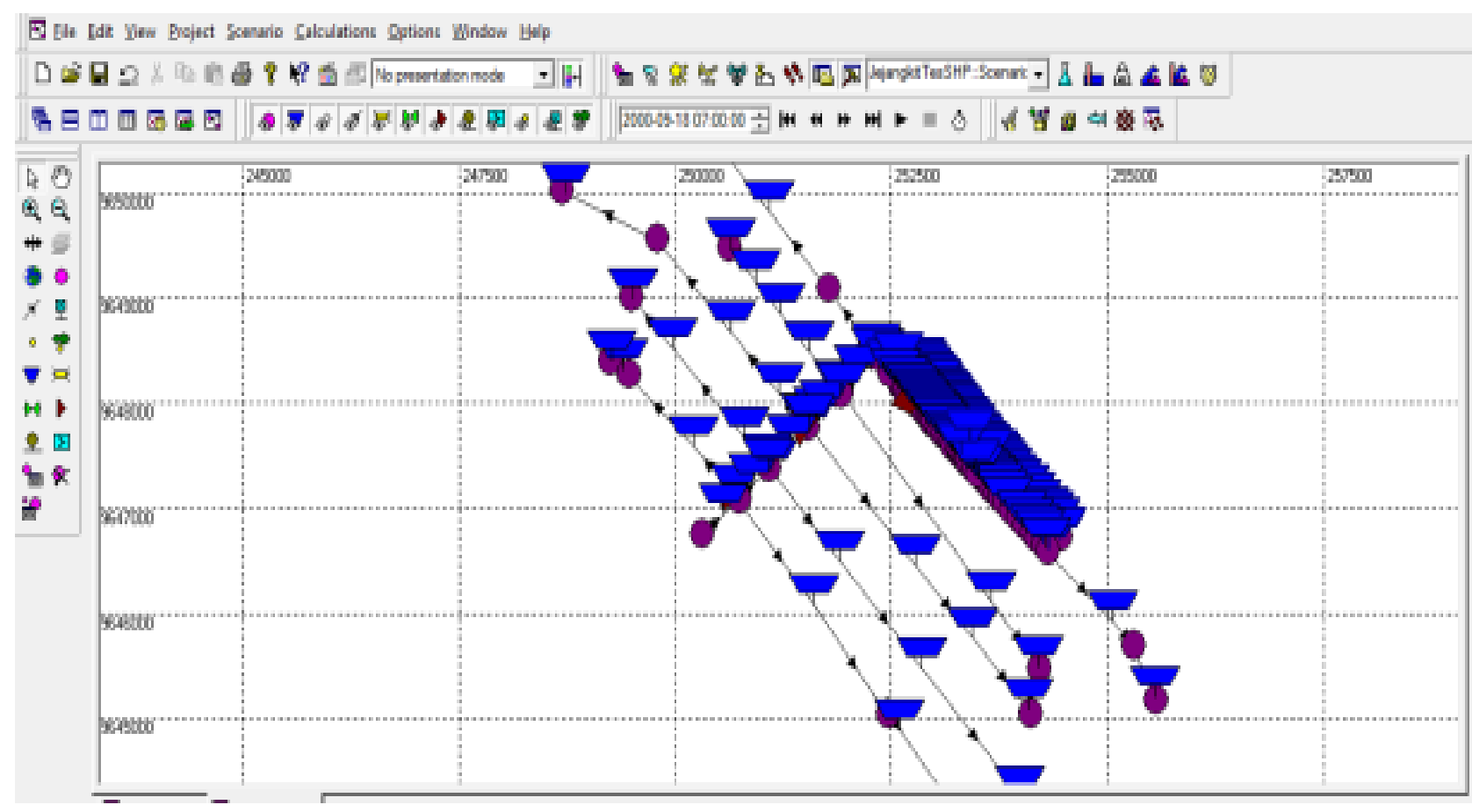

Gambar 7 Hasil Model Unit Rawa Jejangkit Pada Duflow

Sumber: Hasil Analisa 


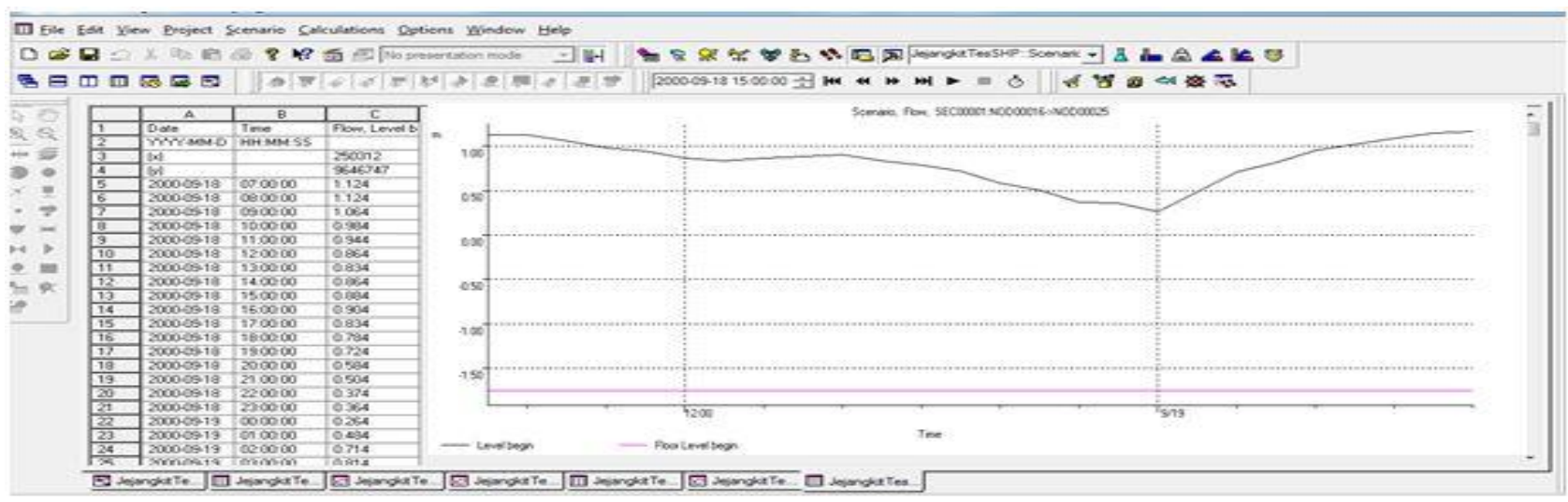

Gambar 8 Hasil Simulasi Pasang Surut Pada Model Sumber: Hasil Analisa

Gambar diatas menunjukkan bahwa model berjalan dengan stabil, ditunjukkan oleh pergerakan muka air pasang surut yang stabil Hasil model yang telah stabil kemudian dilakukan kalibrasi. Kalibrasi dilakukan dengan uji regresi sederhana dan uji RMSE (root mean square error).

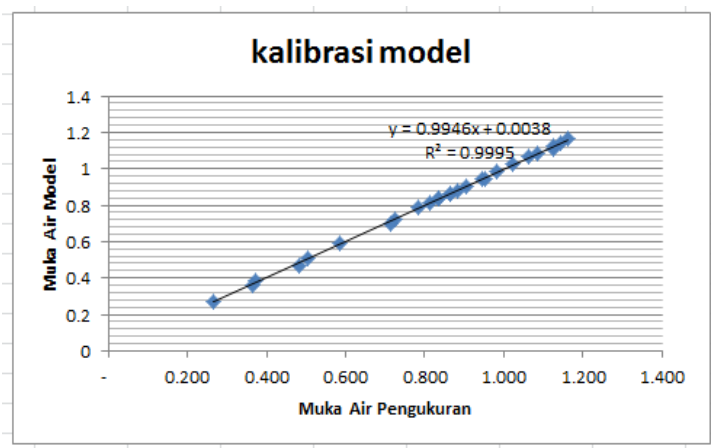

Gambar 9 Uji Regresi Sederhana

Sumber: Hasil Analisa

Berdasarkan tabel 2 maka nilai RMSE nya adalah :

$\mathrm{RMSE}=\sqrt{\frac{1}{n} \sum_{i=1}^{n}(h e-h r)^{2}}$

RMSE $=0.005881214$

Perhitungan menunjukkan bahwa nilai RMSE sangat kecil dan mendekati nol.

Dari dua pengujian diatas menunjukkan bahwa nilai $\mathrm{R}^{2}$ (koefisien determinasi) lebih besar dari 0,75 dan nilai Root Mean Square Error (RMSE) sangat kecil dan mendekati nol, sehingga model dikatakan baik
Tabel 2 Uji RMSE

\begin{tabular}{|c|c|c|c|c|}
\hline NO & $\begin{array}{c}\text { Muka air } \\
\text { Pengukuran (de) }\end{array}$ & $\begin{array}{l}\text { Muka Air } \\
\text { Model (dr) }\end{array}$ & (he-hr) & $(h e-h r) 2$ \\
\hline 1 & 1.124 & 1.11175 & 0.012 & 0.000150063 \\
\hline 2 & 1.124 & 1.12612 & $(0.002)$ & $4.4944 E-06$ \\
\hline 3 & 1.064 & 1.06493 & $(0.001)$ & $8.6495-07$ \\
\hline 4 & 0.984 & 0.986026 & $(0.002)$ & $4.10468 \mathrm{E}-06$ \\
\hline 5 & 0.944 & 0.945018 & $(0.001)$ & $1.03632 \mathrm{E}-06$ \\
\hline 6 & 0.864 & 0.866114 & $(0.002)$ & $4.469 E-06$ \\
\hline 7 & 0.834 & 0.834792 & $(0.001)$ & $6.27264 \mathrm{E}-07$ \\
\hline 8 & 0.864 & 0.863842 & 0.000 & $2.4964 E-08$ \\
\hline 9 & 0.884 & 0.882626 & 0.001 & $1.88788 \mathrm{E}-06$ \\
\hline 10 & 0.904 & 0.904548 & $(0.001)$ & $3.00304 \mathrm{E}-07$ \\
\hline 11 & 0.834 & 0.835589 & $(0.002)$ & $2.52492 \mathrm{E}-06$ \\
\hline 12 & 0.784 & 0.785378 & $(0.001)$ & $1.89888 \mathrm{E}-06$ \\
\hline 13 & 0.724 & 0.725544 & $(0.002)$ & $2.38394 \mathrm{E}-06$ \\
\hline 14 & 0.584 & 0.592631 & $(0.009)$ & $7.44942 \mathrm{E}-05$ \\
\hline 15 & 0.504 & 0.507769 & $(0.004)$ & $1.42054 \mathrm{E}-05$ \\
\hline 16 & 0.374 & 0.382805 & $(0.009)$ & $7.7528 E-05$ \\
\hline 17 & 0.364 & 0.364354 & $(0.000)$ & $1.25316 \mathrm{E}-07$ \\
\hline 18 & 0.264 & 0.270408 & $(0.006)$ & $4.10625 \mathrm{E}-05$ \\
\hline 19 & 0.484 & 0.469823 & 0.014 & 0.000200987 \\
\hline 20 & 0.714 & 0.697923 & 0.016 & 0.00025847 \\
\hline 21 & 0.814 & 0.80974 & 0.004 & $1.81476 \mathrm{E}-05$ \\
\hline 22 & 0.954 & 0.948178 & 0.006 & $3.38957 \mathrm{E}-05$ \\
\hline 23 & 1.024 & 1.02264 & 0.001 & $1.8496 E-06$ \\
\hline 24 & 1.084 & 1.08349 & 0.001 & $2.601 E-07$ \\
\hline 25 & 1.144 & 1.14292 & 0.001 & $1.1664 \mathrm{E}-06$ \\
\hline 26 & 1.164 & 1.16244 & 0.002 & $2.4336 \mathrm{E}-06$ \\
\hline \multicolumn{3}{|c|}{ TOTAL } & 0.017 & 0.000899306 \\
\hline
\end{tabular}

Sumber: Hasil Analisa

\section{Analisa Kondisi Eksisting}

Dari hasil pemodelan lahan eksisting setelah di lakukan running test (uji model) maka menghasilkan muka air yang ditunjukan pada gambar 10 berikut: 


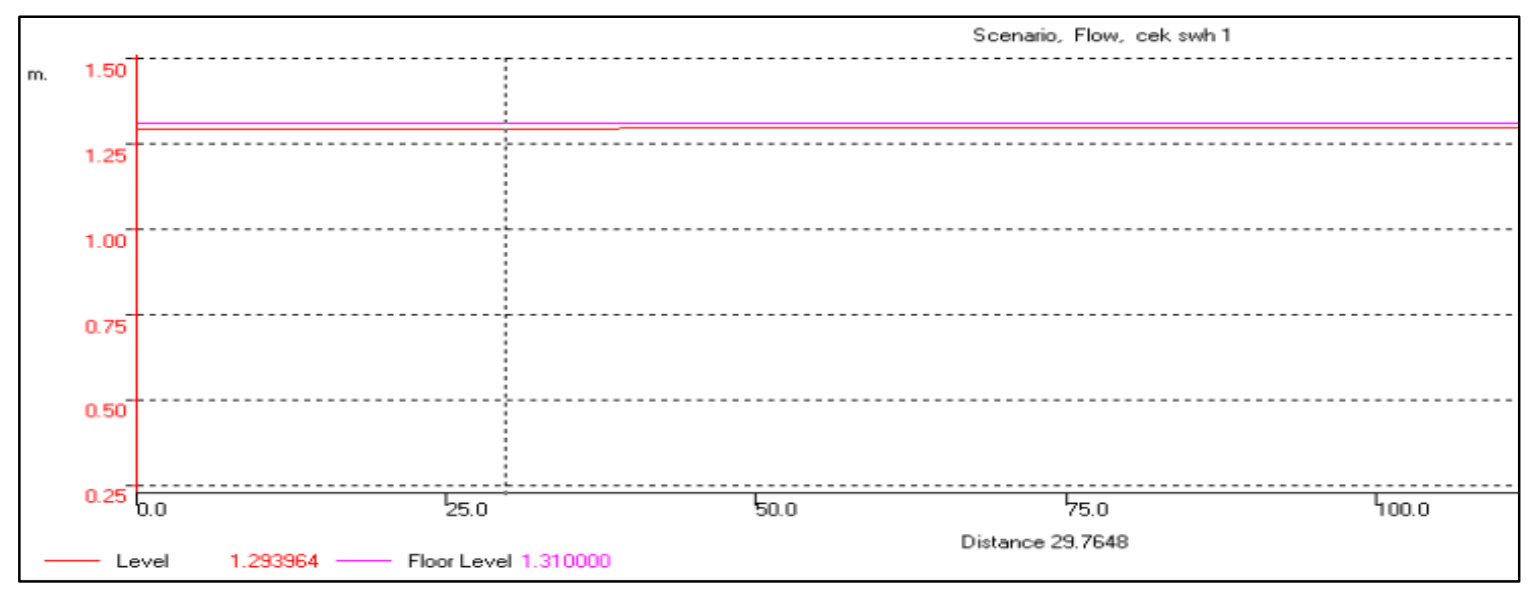

Gambar 10 Grafik Kondisi Muka Air Eksisting Lahan Pada Duflow Sumber: Hasil Analisa

Kondisi eksiting lahan pada hasil model menunjukkan bahwa level (tinggi muka) air berada pada 1,293 $\mathrm{m}$ dan floor level (dasar lahan) berada pada $1,31 \mathrm{~m}$. hal ini menunjukkan bahwa pada lahan tidak terjadi penggenangan atau tidak ada air dilahan. Keadaan ini tentu sangat tidak mungkin untuk dilakukan penanaman tanaman budi daya terutama padi yang memerlukan adanya genangan air setinggi $20 \mathrm{~cm}$. serta kemungkinan resiko untuk teroksidasinya pirit bisa terjadi karena tidak adanya genangan air.

\section{Pemecahan Masalah Pada Lahan}

Dari hasil analisa terhadap lahan sebelumnya di ketahui bahwa lahan tidak mendapatkan suplai air yang cukup sehingga perlu tambahan suplai air untuk dapat memenuhi kebutuhan air pada saat penanaman dan mencegah terjadinya oksidasi pirit. Dalam studi ini rekomendasi yang di berikan adalah dengan menggunakan pompa. Adapun beberapa alternative penempatan pompa yang di rekomendasikan adalah:

1. Di muara saluran primer

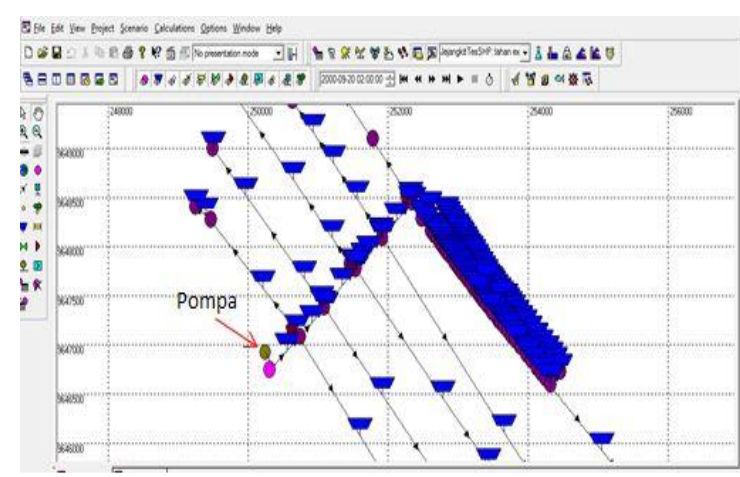

Gambar 11 Pompa di Muara Primer Pada Duflow

Sumber: Hasil Analisa
Untuk menentukan besarnya debit pompa maka dilakukan uji coba-coba (Trial) seperti pada tebel 3 di bawah ini

Tabel 3 Trial Debit Pompa di Muara Primer

\begin{tabular}{|c|c|c|c|}
\hline No & $\begin{array}{c}\text { Debit Pompa } \\
\left.\text { Trial ( } \mathrm{m}^{3} / \text { detik }\right)\end{array}$ & $\begin{array}{c}\text { Waktu } \\
(\mathrm{Jam})\end{array}$ & $\begin{array}{c}\text { Tinggi Muka Air } \\
(\mathrm{m})\end{array}$ \\
\hline 1 & 0,01 & 72 & 1,16 \\
\hline 2 & 0,05 & 72 & 1,18 \\
\hline 3 & 0,1 & 72 & 1,21 \\
\hline 4 & 0,5 & 72 & 1,40 \\
\hline 5 & 1 & 34 & 1,51 \\
\hline 6 & 1,5 & 22 & 1,51 \\
\hline 7 & 2 & 15 & 1,51 \\
\hline 8 & 2,5 & 12 & 1,51 \\
\hline 9 & 3 & 9 & 1,51 \\
\hline 10 & 3,5 & 8 & 1,51 \\
\hline 11 & 4 & 6 & 1,51 \\
\hline
\end{tabular}

Sumber: Hasil Analisa

2. Muara saluran tersier

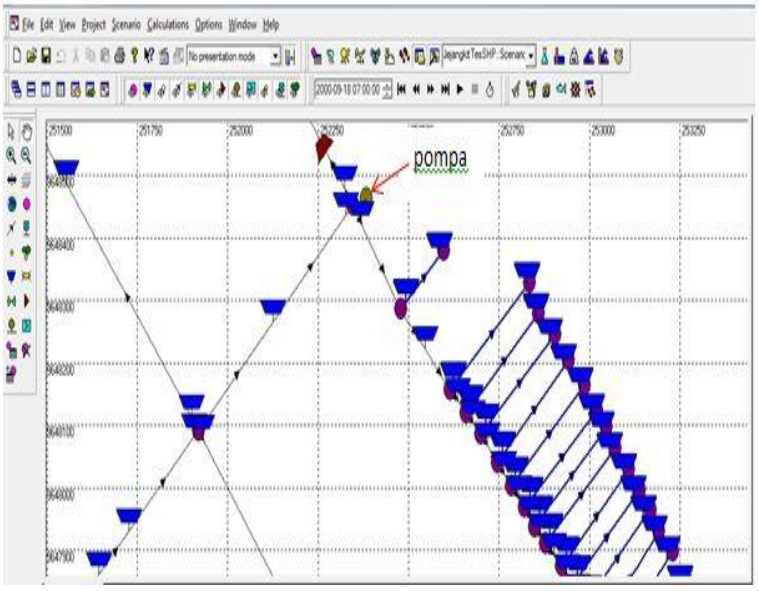

Gambar 12 Pompa di Muara Tersier Pada Duflow Sumber : Hasil Analisa 
Tabel 4 Trial Debit Pompa di Tersier

\begin{tabular}{|c|c|c|c|}
\hline No & $\begin{array}{c}\text { Debit Pompa } \\
\text { Trial (m/detik) }\end{array}$ & $\begin{array}{c}\text { Waktu } \\
(\mathrm{Jam})\end{array}$ & $\begin{array}{c}\text { Tinggi Muka Air } \\
(\mathrm{m})\end{array}$ \\
\hline 1 & 0,01 & 72 & 1,22 \\
\hline 2 & 0,05 & 72 & 1,47 \\
\hline 3 & 0,1 & 27 & 1,51 \\
\hline 4 & 0,2 & 13 & 1,51 \\
\hline 5 & 0,3 & 8,5 & 1,51 \\
\hline 6 & 0,4 & 6 & 1,51 \\
\hline 7 & 0,5 & 4,5 & 1,51 \\
\hline 8 & 1 & 1,5 & 1,51 \\
\hline
\end{tabular}

sumber: Hasil Analisa
Untuk penentuan debit pompa pada muara tersier juga di lakukan uji trial seperti yang di tunjukkan pada Tabel 4. Hal ini dilakukan untuk menaikan muka air pada lahan menjadi $1.51 \mathrm{~m}$

Penempatan pompa pada saluran primer dan muara saluran tersier berdampak positif pada lahan hal ini ditunjukkan pada model terjadi kenaikan level air seperti yang ditunjukkan pada gambar 13 . Dengan naiknya tinggi muka air pada lahan maka lahan akan mendapatkan suplai air untuk penanaman

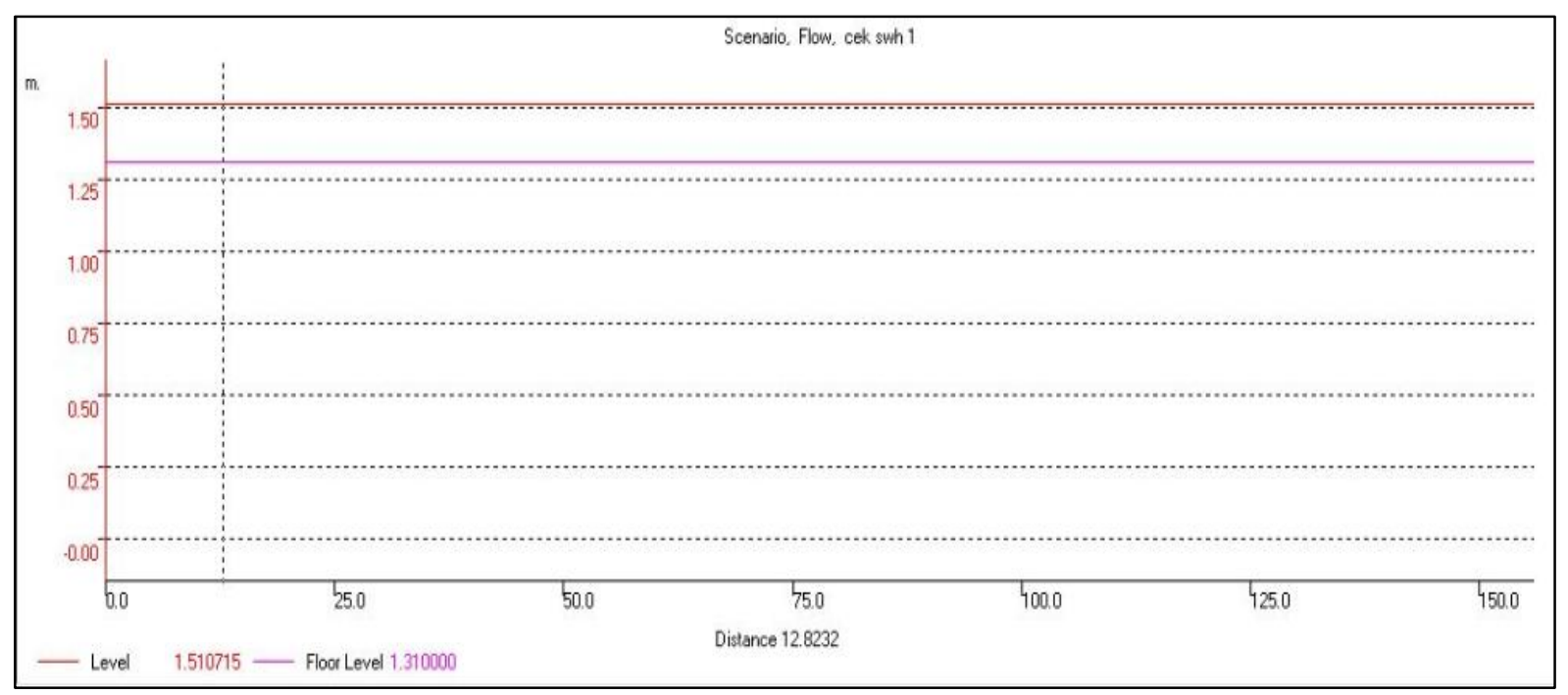

Gambar 13 Grafik Kondisi Muka Air Setelah Adanya Pompa di Lahan Pada Duflow Sumber: Hasil Analisa

\section{Pemilihan dan Pengoperasian Pompa}

Untuk mengetahui jenis pompa yang dapat digunakan dapat menggunakan monogram pemilihan pompa di bawah ini:

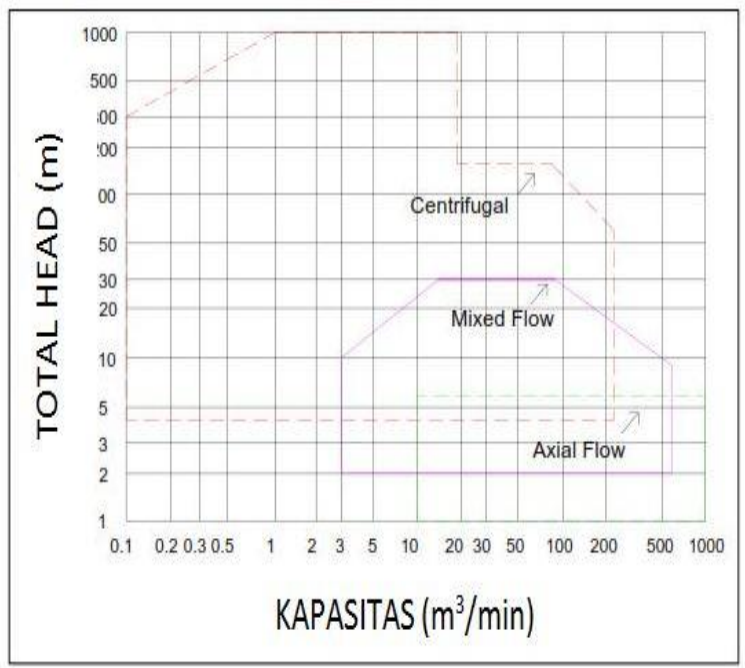

Gambar 14 Monogram Pompa Sumber : Ditjen Cipta Karya,2013
Dari hasil running pada model, untuk memenuhi kebutuhan air pada lahan baik dengan penempatan pompa di muara primer dan penempatan pompa di muara tersier yang masing-masing dapat di ketahui bahwa debit pompa minimal yang di butuhkan adalah adalah $1 \mathrm{~m}^{3} /$ detik untuk di muara primer dan $0,1 \mathrm{~m}^{3} /$ detik. Jika total head pompa adalah 7 $\mathrm{m}$,maka pompa yang direkomendasikan untuk dipakai berdasarkan monogram pemilihan pompa diatas adalah pompa berjenis sentrifugal

\section{Pengaruh Penggenangan Terhadap Kera- cunan Senyawa Besi (Pirit)}

Berdasarkan studi yang telah dilaksanakan sebelumnya oleh Balai Rawa pada tahun 2013 disebutkan bahwa ray rawa Jejangkit memiliki kandungan pirit terkuat rata-rata pada kedalaman 0-20 cm dibawah lapisan atas (top soil) dengan $\mathrm{pH}$ tanah 25 di suhu $35^{\circ} \mathrm{C}$, sedangkan kandungan pirit sedang rata-rata pada kedalaman 40-60 $\mathrm{cm}$ dengan $\mathrm{pH}$ tanah 34 di suhu $33^{\circ} \mathrm{C}$, dan kandungan pirit lemah 
rata-rata pada kedalaman $80-100 \mathrm{~cm}$ dengan $\mathrm{pH}$ tanah 44 di suhu $37^{\circ} \mathrm{C}$.

Seperti yang sudah, bahwa kondisi pirit akan stabil dan aman jika berada di bawah lapisan air. Hal ini berarti bahwa potensi teroksidasinya pirit akan tidak ada hanya jika lapisan air berada di atas atau menggenangi lapisan pirit terus menerus di samping sebagai usaha pencucian pirit dan senyawa beracun lainnya

Menurut Bambang Priadmadi, 2009; analisa kimiawi dan reaksi kimiawi jika terjadi proses penggenangan lapisan pirit adalah sebagai berikut :

$\mathrm{FeS}_{2}+2 \mathrm{H}_{2} \mathrm{O} \rightleftarrows \mathrm{Fe}+2 \mathrm{H}_{2} \mathrm{~S}+\mathrm{O}_{2}$ Jika lapisan pirit $\left(\mathrm{FeS}_{2}\right)$ terendam air $\left(\mathrm{H}_{2} \mathrm{O}\right)$, maka proses ini akan berlanjut dengan terbentuknya gas sulfide $\left(\mathrm{H}_{2} \mathrm{~S}\right)$ yang dicirikan dengan bau yang menusuk hidung dan oksigen $\left(\mathrm{O}_{2}\right)$. Hal ini akan lebih baik jika kondisi air selalu mengalir sehingga proses pencucian senyawa racun akan berlangsung (yuliana,2010)

Dari hasil pengujian model baik dengan penempatan pompa pada muara saluran primer dan penempatan pompa pada muara saluran sekunder keduanya mampu membuat lahan pada ray 5 tergenang dengan tinggi genangan $18 \mathrm{~cm}$ sampai dengan $20 \mathrm{~cm}$ di atas permukan lapisan atas (top soil). Dengan adanya penggenangan pada lahan maka resiko teroksidasinya pirit tidak akan terjadi (Mariana,2013).

Pencucian senyawa pirit dilakukan melalui mekanisme ilmiah yang telah disediakan oleh alam sendiri yaitu aliran sungai. Mekanisme aliran sungai adalah pada saat air di pompa, air di biarkan masuk ke lahan-lahan pertanian (Mahfuzi,2009). Dengan demikian akan terjadi penggenangan selama waktu pengisian tersebut. Kemudian pada waktu surut air pada lahan akan menyusut sehingga terjadi penurunan genangan dan air akan kembali ke sungai dengan membawa racun-racun yang terlarut di dalamnya.

\section{KESIMPULAN DAN SARAN}

\section{Kesimpulan}

Berdasarkan hasil analisis pada lahan rawa pada Kecamatan Jejangkit dengan menggunakan aplikasi Duflow, maka dapat disimpulkan sebagai berikut:

1. Lahan rawa Jejangkit memiliki kondisi daerah lahan persawahan yang kering terutama di lahan persawahan tersier (ray) 5. Hal ini ditunjukan oleh tinggi muka air yang terjadi pada lahan hanya berada di 1,293 m, sedangkan tinggi elevasi dasar lahan berada di 1,31. Yang artinya lahan dalam kondisi kering karena air yang berada pada sistem tata air tidak mampu mensuplai air pada lahan.

2. Pasang tertinggi yang berada pada $1,164 \mathrm{~m}$ tidak mampu memberikan suplai air pada lahan.

3. Lahan sawah dalam kondisi seperti ini tidak mungkin dilakukan penanaman tanaman padi. Dan resiko untuk terjadinya oksidasi pirit sangat mungkin terjadi.

4. Untuk mengatasi permasalahan kebutuhan air pada lahan rawa Jejangkit maka di gunakan pompa untuk memberikan suplai air pada lahan. Adapun alternatif penempatan pompa adalah sebagai berikut:

a. Pompa ditempatkan pada muara saluran primer. Debit pompa yang diperlukan untuk menaikan tinggi muka air pada lahan pada alternatif ini minimal $1 \mathrm{~m}^{3} / \mathrm{s}$ dengan waktu penggenangan 34 jam. Untuk jumlah pompa yang di gunakan tidak ada batasan selama jumlah pompa di pakai tidak kurang dari $1 \mathrm{~m}^{3} / \mathrm{s}$. Debit pompa juga berpengaruh dengan waktu penggenangan semakin besar debit semakin cepat waktu penggenangan yang terjadi.

b. Pompa ditempatkan pada muara saluran tersier. Debit pompa yang di perlukan untuk dapat mampu meninggikan muka air setinggi $20 \mathrm{~cm}$ pada lahan pada alternatif ini minimal $0,1 \mathrm{~m}^{3} / \mathrm{s}$ dengan waktu penggenangan 27 jam. Untuk jumlah pompa yang di gunakan tidak ada batasan selama jumlah pompa di pakai tidak kurang dari $0,1 \mathrm{~m}^{3} / \mathrm{s}$. Debit pompa juga berpengaruh dengan waktu penggenangan semakin besar debit semakin cepat waktu penggenangan yang terjadi.

5. Kondisi lahan persawahan pada unit rawa Kecamatan Jejangkit khususnya pada tersier (ray) 5 setelah adanya pompa adalah a. Muka air pada lahan berada di elevasi $1,51 \mathrm{~m}$ yang artinya terdapat genangan air setinggi $20 \mathrm{~cm}$ pada lahan.

b. Lahan dapat ditanami, sehingga petani yang semula hanya bisa panen satu kali 
satu tahun di musim penghujan menjadi dua kali setahun (musim penghujan dan musim kemarau)

c. Dengan adanya genangan diatas lahan resio teroksidasinya pirit tidak akan terjadi.

\section{Saran}

Adapun saran terkait dengan proses dan hasil yang diperoleh pada studi ini adalah sebagai berikut:

1. Perlu dilakukan uji coba model fisik untuk menguji keberhasilan sistem tata air dengan penerapan pompa pada unit rawa Kecamatan Jejangkit.

2. Perlu dilakukan uji analis lebih dalam mengenai dampak sosial, ekonomi dan lingkungan dengan adanya pompa sebagai sumber tambahan suplai air pada unit rawa Kecamatan Jejangkit.

3. Perlu diadakan uji lab lanjutan untuk mengetahui bagaimana pengaruh genangan $20 \mathrm{~cm}$ terhadap lahan sawah di ray 5 Kecamatan Jejangkit.

\section{DAFTAR PUSTAKA}

Badan Pusat Statistik Kabupaten Barito Kuala, 2015, Statistik Daerah Kecamatan Jejangkit 2015, Badan Pusat Statistik Kabupaten Barito Kuala.

Balai Rawa, 2014, Laporan Akhir Kegiatan Penelitian Optimasi Jaringan Tata Air Daerah Rawa: Kasus Studi DIR. Jejangkit, Pusat Litbang Sumber Daya Air, Kementerian Pekerjaan Umum.

Direktorat Jenderal Cipta Karya,2013,Tata Cara Perencanaan, Pelaksanaan, Operasi Dan Pemeliharaa Sistem Pompa, Kementerian Pekerjaan Umum.
Hadisusanto, Nugroho.2010. Aplikasi Hidrologi. Jogya Mediautama. Malang

Khairullah, Izhar and Sarwani,Muhrizal. 2012. Technology Of Iron Toxicity On Rice At Acid Sulfate Soil Of Tidal Swamp Lands. Indonesian Wetland Research Institute

Mahfuzi.2009. Kajian Tata Air Mikro (TAM) Sebagai Reduktor Oksidasi Pirit Di Daerah Rawa (DR) Sungai Kupang Kalimantan Selatan.Tesis. Fakultas Teknik Universitas Brawijaya Malang

Mariana, Zuraida,2013. Kajian Perubahan Kemasaman Tanah Akibat Penggenangan,Pengelolaan Hidrologi Pasang Surut Kalimantan Selatan. Fakultas Pertanian Universita Lambung Mangkurat, Banjarbaru

Pemerintah Republik Indonesia, 2013, Peraturan Pemerintah Republik Indonesia Nomor 73 tentang Rawa, Pemerintah Republik Indonesia.

Priatmadi, Bambang Joko dan Haris, Abdul, 2009, Reaksi Pemasaman Senyawa Pirit pada Tanah Rawa Pasang Surut.Jurnal Tanah Tropika Tahun 2009, 14.

Suhardjono,Prasetyorini,linda,Haribowo,Riya nto.2010. Reklamasi Daerah Rawa. Cv. Citra Malang.Malang

Yuliana, Dewi, 2010. Uji Sifat Kimia Tanah Berpirit Akibat Lama Pengeringan Dan Kedalaman Muka Air Tanah. Jurnal Ilmiah, Universitas Hindu Indonesia Denpasar. 